\title{
Renata Iwicka*
}

\section{Beethoven alias Wilson \\ - ironia u Akutagawy jako remedium na chaos}

DOI: http://dx.doi.org/10.12775/LC.2017.060

Streszczenie: Okres Taishō (1912-1926), choć trwał ledwie czternaście lat, to jednak stał się areną nieprawdopodobnej wręcz żywotności literackiej. Jest to okres łączący skrajności - z jednej strony Japonia narzucała swoje kolonialne prawa innym narodom Azji, a z drugiej literaci spierali się o rolę fabuły w powieści; cenzura i wzrastająca militaryzacja oraz nacjonalizacja kraju istniały (przynajmniej przez jakiś czas) razem z kinami i dancingami. Podążano za zachodnimi modami, prądami naukowymi, literaturą, ale cały czas oglądano się wstecz na własną tradycję. Podobna dychotomia wydawała na świat artystów - czujących się nie do końca pewnie ani w rodzimej, ani w zachodniej kulturze. Ze splątania czasem nieprzystających wartości i ideałów tworzył się chaos. W takim okresie tworzył Akutagawa Ryūnosuke (1892-1927), który w konsekwentny sposób trzymał tę kotłującą się masę podszytą destrukcyjnym absurdem i nihilizmem za kratami uporządkowanej struktury literackiej nasyconej humorem i ironią jako mechanizmami obronnymi. Kiedy zarówno jego zdrowie, jak i struktura tworzonych utworów zaczęły ulegać dezintegracji - chaos zapanował nad życiem Akutagawy, który wbrew Camusowi nie wybrał rewolucji, ale samobójstwo. Artykuł analizuje elementy humoru oraz ironii obecnych w utworach Akutagawy charakteryzujących się trzema widocznymi stopniami rygoru kompozycji - od najwcześniejszych, uporządkowanych, po dystopijną, luźną narrację, która jednakże do końca próbowała wygrać z chaosem w umyśle pisarza. Humor oraz ironia były elementami strukturalnymi służącymi oswajaniu świata pełnego zagrożeń - zarówno Japonii lat dwudziestych, jak i wewnętrznego, pełnego lęków umysłu pisarza.

Słowa kluczowe: Akutagawa Ryūnosuke, humor, ironia, Japonia, opowiadanie, Taishō

\footnotetext{
Absolwentka Instytutu Filologii Orientalnej Uniwersytetu Jagiellońskiego, dr kulturoznawstwa, obecnie adiunkt w Katedrze Porównawczych Studiów Cywilizacji UJ. Jej badania obejmują: szeroko pojętą demonologię, kulturę i historię Azji (zwłaszcza Japonii i Korei), mitologię i popkulturę. E-mail: grad_ecmaise@yahoo.com.
} 


\title{
Beethoven alias Wilson
}

\section{- Akutagawa's irony as a remedy against chaos}

\begin{abstract}
Taishō period (1912-1926) lasted for a total of 14 years, and yet it produced an astonishing number of literary and artistic works. It was the time of an intellectual and socio-political bifurcation. On the one hand, Japan had dancing-halls, movie theatres, girls and boys copying the behaviour of their western counterparts. On the other hand, it had censorship, political persecutions, violence and colonial dominions abroad. Western ideas, trends and thoughts mixed with Japanese ones. This created a situation when a person could not identify with either, having incorporated both western and Japanese tradition. A person could perceive the world as a fumbling chaos of different ideas and values. Most likely that was the case of Akutagawa Ryunnosuke (1892-1927) who tried to hold back the chaos of both the outside world and his inner one with a meticulously prepared layout for his stories and fenced off with humor and irony. The article tries to analyze how Akutagawa implemented humour and irony in his work - divided into three periods starting from his early works that display a rigorously crafted story and ending with his last works, devoid of any optimistic and light humour and filled with bleak irony and dystopian absurdity. Humour and irony were the means to deal with the increasingly chaotic political and social life in Japan, as well as the last stand between Akutagawa and the dark, nihilistic chaos that grew in his own mind.
\end{abstract}

Keywords: Akutagawa Ryūnosuke, humour, irony, Japan, short story, Taishō

ro-guro-nansensu ${ }^{1}$ - to skondensowana charakterystyka okresu Taishō (1912-1926), na który przypada twórczość Akutagawy Ryūnosuke (1892-1927). Był to okres przejściowy, testowy, kiedy Japonia eksperymentowała z demokracją i poniosła porażkę, czas moga oraz mobo, sporów dotyczących natury literatury, lata, które na Zachodzie określa się jako „Roaring Twenties”, czas kiedy walka klasowa i ideologiczna nabierała rozpędu. Dynamika i wewnętrzne sprzeczności epoki stanowiły jeden z motywów twórczości Akutagawy, a bardzo często współczesne mu społeczeństwo stawało się ofiarą jego bardzo subtelnej, precyzyjnej ironii. Twórczość pisarza to nie tylko wyrafinowana, psychologiczna głębia bohaterów, to także humor, który pozwalał przetrwać chaos zewnętrznego, a w przypadku Akutagawy także wewnętrznego świata. Cel artykułu stanowi próba prześledzenia formy i roli ironii w twórczości pisarza - przede wszystkim, w jaki sposób jest implementowana, przeciwko komu wymierzona, jaką funkcję spełnia na płaszczyźnie wybranych utworów. Jednocześnie też praca ma charakter propedeutyczny, z konieczności skrótowy, omówienie całości literackich dokonań Akutagawy w zakresie humoru przekracza objętość jednego tekstu.

\footnotetext{
1 Skrót pochodzi od japońskich słów oznaczających kolejno: erotykę, groteskę i nonsens. Więcej na ten temat: M. R. Silverberg, Erotic Grotesque Nonsense: The Mass Culture of Japanese Modern Times, Berkeley 2006.
} 


\section{Metodologia}

Analiza opowiadań ${ }^{2}$ Akutagawy została przeprowadzona mniej z użyciem metod wypracowanych przez hermeneutykę Hansa-Georga Gadamera ${ }^{3}$, która stanowi użyteczne narzędzie badania tekstów literackich zarówno odległych epok, jak i kultur pozaeuropejskich ${ }^{4}$, a bardziej dzięki spojrzeniu Nowego Historyzmu, który każe czytać wszystkie teksty kultury, zrównując je ze sobą ${ }^{5}$. Dodatkowo, ważną kwestią jest umiejscowienie tekstu w przestrzeni historycznej jako determinanty każdej twórczości artystycznej i jego analiza właśnie z tego punktu widzenia. Więcej - istotne wydaje się zarówno gadamerowskie zanurzenie się, sięgnięcie ku danemu tekstowi i kulturze, w jakiej powstał. Motyw ironii, a tym samym i humoru, każe sięgnąć po metodę Bachtinowskiego ${ }^{6}$ odczytania świata, który zbudowany jest $\mathrm{z}$ wielu wzajemnie komplementarnych płaszczyzn. Wprawdzie utwory Akutagawy nie przypominają dzieła Rabelais'go, a koncept karnawału jest obcy kulturze japońskiej, to jednak pewne elementy funkcji humoru zdają się do siebie podobne. Jak pisze bowiem Andrzej Bełkot, który reinterpretuje myśl Bachtina, a którego rozważania bardziej pasują do świata literatury Akutagawy: „[z] jednej strony przyjęcie zasady karnawału oznaczać może rozumienie i przeżywanie głębokiej polifonicznej struktury świata, w myśl Bachtinowskiego »światoodczucia «; z drugiej skazywać może na permanentne i destrukcyjne kwestionowanie każdego systemu wartości i ładu społecznego, w myśl wesołej względności świata”. Karnawał odwracał porządek rzeczy i wyszydzał to, czego w zwyczajnym czasie wyszydzić nie było można - podobnie też postąpił Akutagawa w Kappach - koszmarnie dystopijnym ${ }^{8}$ świecie, który z czasem staje się bliższy bohaterowi niż świat ludzi.

Stownik języka polskiego definiuje ironię jako „ukrytą drwinę, utajone szyderstwo, złośliwość zawartą w wypowiedzi pozornie aprobującej” i dodaje, że „satyra operować może ironią i sarkazmem, szlachetnym patosem i subtelnym żartem" " Z kolei znakomity polski literaturoznawca, Michał Głowiński, pisze o ironii, że musi zostać zidentyfikowana, może być subtelna i wypełniać szczeliny powstałe między narratorem a postaciami, a także że:

\footnotetext{
2 Używam słowa „opowiadanie”, choć w „Bungei shunjū”, czasopiśmie literackim, które publikowało utwory literackie Akutagawy, jego historie były zamieszczane w dziale zuihitsu, czyli szkiców, esejów. Por. R. DiNitto, Return of the "Zuihitsu": Print Culture, Modern Life, and Heterogeneous Narrative in Prewar Japan, "Harvard Journal of Asiatic Studies" 2004, Vol. 64, No. 2, s. 251-290.

3 H.-G. Gadamer, Prawda i metoda: zarys hermeneutyki filozoficznej, tłum. B. Baran, Warszawa 2015.

4 Współczesna metodologia badań literackich jest kwestią wykraczająca poza ramy tego artykułu. Autorka posiłkuje się narzędziami wypracowanymi przez wiele szkół i nurtów, przede wszystkim czerpiąc z dokonań Nowego Historyzmu, postkolonializmu i szeroko pojętej antropologii literatury. Por. J. Culler, Teoria literatury, tłum. M. Bassaj, Warszawa 1998; oraz Antropologia twórczości słownej. Zagadnienia i wybór tekstów, red. A. Karpowicz, K. Hagmajer-Kwiatek, J. Kowalska-Leder, Warszawa 2012.

5 Więcej na ten temat na przykład w: R. Selden, P. Widdowson, P. Brooker, A Reader's Guide to Contemporary Literary Theory, Harlow 2005; oraz S. J. Greenblatt, Learning to Course. Essays in Early Modern Culture, London 1990.

6 M. Bachtin, Twórczość Franciszka Rabelais'go a kultura ludowa Średniowiecza i Renesansu, tłum. A. i A. Goreń, Kraków 1975.

7 A. Bełkot, Karnawalizacja jako pojęcie ludyczne, „Homo Communicativus” 2010, nr 4, s. 52.

8 Dystopia nie jest tylko prostym przeciwieństwem utopii - jest celowo wypaczonym, tragicznym światem, z którego nie ma ucieczki. Pierwszy raz pojęcie zostało wprowadzone w roku 1747, prawdopodobnie przez Lewisa Henry'ego Younge'a; por. K. M. Maj, Eutopie i dystopie. Typologia narracji utopijnych z perspektywy filozoficzno-literackiej, „Ruch Literacki” 2014, R. LV, z. 2 (323), s. 161.

9 Słownik języka polskiego, red. W. Doroszewski, Warszawa; wersja elektroniczna dostępna na stronie: http:// www.sjp.pwn.pl/doroszewski/ [dostęp: 20.08.2016].
} 
Poza użyciami ewidentnymi, określonymi przez sytuację, w której dane słowa padły, przez kontekst, przez naszą wiedzę (o charakterze ogólnym bądź jednostkowym, gdy rzecz odnosi się do zjawisk poszczególnych), a wreszcie przez właściwości kultury, w której dane wypowiedzenie funkcjonuje, ironia jest dziedziną mówienia ryzykownego - tak w potocznym kontakcie językowym, jak w literaturze. Zresztą granice między tym, co oczywiste, a tym, co wymaga indywidualnej reakcji od odbiorcy i zakłada jego wysiłek, zmierzający do zrozumienia tekstu, są plynne i w wielu wypadkach nie dadzą się precyzyjnie wyznaczyćc ${ }^{10}$.

Elementy humoru i ironicznej krytyki ${ }^{11}$ występują w wielu dziełach Akutagawy, między innymi Negi, Chigi, Uma no ashi, Saru kani gassen, Hyotokko, Kappy, Shōgun ${ }^{12}$. Na potrzeby artykułu zajęłam się tylko trzema: Negi (Cebulki), Saru kani gassen (Walka kraba z matpa) oraz Kappy, z czego najwięcej uwagi zostanie poświęcone pierwszemu opowiadaniu.

\section{Charakterystyka utworów Akutagawy}

Najwcześniejsze utwory Akutagawy cechuje uporządkowanie, są zbudowane na zachodnim wzorcu narracyjnym opowiadania, posiadając wstęp, rozwinięcie i zakończenie. Wszystkie elementy są osadzone w strukturze w sposób perfekcyjny i zaplanowany ${ }^{13}, \mathrm{w}$ tym także humor - jest on lekki, niemalże ażurowy. Im bliżej jednak 1927 roku, tym bardziej ten humor mroczniał, zmieniał się w groteskowe wykoślawienie świata. Wraz z upływem lat rozsypywała się również struktura opowiadań, kiedy pod presją krytyków i w wyniku własnych poszukiwań zaczął wprowadzać elementy autobiograficzne do utworów. W przypadku Akutagawy zatem trudno zgodzić się z postulatami Rolanda Barthes’a o „śmierci autora” i nadrzędnej funkcji samego języka czy też „pisania” ${ }^{14}$, gdyż ostatnie lata twórczości pisarza są głęboko naznaczone jego własną osobowością i życiorysem, a wewnętrzne lęki, poszukiwanie nowych sposobów ekspresji artystycznej ${ }^{15}$ oraz sytuacja zewnętrzna odcisnęly swoje piętno na utworach, zatem w tym kontekście istotne jest „kto pisze” ${ }^{\prime 6}$. Nie sposób analizować niektórych jego opowiadań bez tego kontekstu.

10 M. Głowiński, Ironia jako akt komunikacyjny, [w:] Ironia, red. M. Głowiński, Gdańsk 2005, s. 9.

11 O ironii pisali również: S. Kierkegaard, The Concept of Irony With Continuous Reference to Socrates (1841), Princeton 1992; R. Rorty, Contingency, Irony and Solidarity, Cambridge 1989; C. Colebrook, Irony, London-New York 2004

12 Wszystkie tłumaczone cytaty utworów pochodzą z otwartego repozytorium zdygitalizowanych tekstów źródłowych Aozora bunko (dostępne pod adresem: http://www.aozora.gr.jp/). Autorka korzystała z tego źródła ze względu na poręczność wersji elektronicznej tekstów, a także ortografię odtwarzającą zapis, w jakim zostały one najwcześniej opublikowane.

13 Według Timothy'ego llesa nawet znaki kanji użyte do zapisu imion są znaczące. Por. T. J. F. Iles, "Akutagawa Ryunosuke:Three Themes", praca magisterska napisana na Uniwersytecie Columbia, New York 1992.

14 Por. R. Barthes, Śmierć autora, tłum. M. P. Markowski, ,Teksty Drugie" 1999, nr 1/2 (54/55), s. 247-251.

15 Akutagawa przyjął stanowisko, że to nie fabuła jest najważniejszym elementem narracji, lecz poetyka czy też liryczność tekstu, w przeciwieństwie do Tanizakiego, który przyznawał najważniejszą rolę właśnie fabule. Takim quasi-afabularnym utworem jest Aru ahō no isshō (Życie pewnego szaleńca), napisane przed śmiercią - to zbiór luźnych, niemal impresjonistycznych szkiców (zuihitsu) powiązanych jedynie postacią bohatera-narratora. Jest to utwór, według mnie, hybrydowy, stojący na pograniczu fabularności i afabularności.

16 Nawet Foucault pomimo prób nie był w stanie zupełnie usunąć pojęcia „autora” ze swoich rozważań. Por. M. Foucault, Kim jest autor?, tłum. M. P. Markowski, [w:] idem, Powiedziane, napisane. Szaleństwo i literatura, red. T. Komendant, Warszawa 1999, s. 199-219. 


\section{Cebulki (Negi)}

Najpełniejszy przykład humorystycznego i ironicznego talentu Akutagawy stanowi bez wątpienia opowiadanie Negi (1919), w którym pisarz do wnętrza narracji wprowadza samego siebie, choć nie jest to utwór autobiograficzny. Negi już od samego początku zapowiada grę z czytelnikiem - Akutagawa w pierwszej linijce zaznacza, że to, co pisze, jest fikcją, na dodatek gonią go terminy, więc pisze to dość późno („Zamierzam tę historię napisać za jednym posiedzeniem, bo termin mija jutro. Choć nie, »zamierzam « nie gra tu żadnej roli. Po prostu muszę to napisać. Co by tu zatem napisać... Cóż, nie pozostaje mi zatem nic innego, jak liczyć na wyrozumiałość czytelników”) ${ }^{17}$. Od początku odbiorca wie, że będzie to fikcja, jakby Akutagawa już samym pierwszym zdaniem odebrał broń krytykom, którzy nazywali go konfabulantem, zarzucali brak oryginalności i pisanie zmyśleń (czyli fikcji właśnie $)^{18}$. Ale też pierwsze zdanie właściwej historii sytuuje narrację w dokładnie zarysowanej rzeczywistości, kpiąc z prób najwierniejszego oddania rzeczywistości przez naturalistów („W pewnej kawiarence w okolicach Shinbōchō w dzielnicy Kanda ${ }^{19}$ pracuje pewna młoda dziewczyna o imieniu Okimi”). Co więcej, słowa „co by tu zatem napisać” można odczytać jako zawoalowany atak we wszystkich tych pisarzy, którzy nie mając niczego interesującego do powiedzenia, coś napisać muszą, więc na przykład opisują swój dzień. Odrzucał naturalizm i „powieść o sobie” (shishōsetsu) jako nieprzystające do jego własnej formy ekspresji artystycznej, zatem wykorzystał okazję, aby wymierzyć w naturalistów ostrze ironii. Przechodzi jako Autor, a także narrator i bohater jednocześnie, przez wszystkie elementy naturalistycznej prozy: dokładne opisy postaci Okimi, jak wygląda jej pokój, co robi w wolnym czasie, aby wreszcie dojść do wielkiego finału - zakupu cebulek.

Czytelnik niemal na bieżąco obserwuje proces pisania, łącznie z wątpliwościami autora, dotyczącymi dalszych losów bohaterki, który przyznaje z desperacją: „możecie zapytać: jak to autor nie wie? Ano nie wiem [wyrzućże to z siebie!], bo muszę to skończyć jeszcze dziś”, obalając tym samym status narratora wszechwiedzącego. Negi jest dowcipną polemiką z niechętnymi mu krytykami, przy jednoczesnym przedstawieniu świata moga („nowoczesnej dziewczyny”) oraz mobo („nowoczesnego chłopaka”) w lekko ironicznym, choć nie szyderczym świetle. Ze zdań wyłania się obraz Okimi jako ciężko pracującej, samotnej, być może nazbyt sentymentalnej dziewczyny moga oraz Tanaki - przedstawiciela mobo. I choć postaci kobiece w prozie Akutagawy bywały najczęściej zgubnymi femme fatale, to młode dziewczyny stoją jeszcze po stronie niewinności i naiwności, a Okimi ogniskuje, jak w soczewce, właśnie te cechy. Razem z nią w kawiarni pracuje Omatsu i pisarz porównuje je w bardzo specyficzny sposób - Okimi jest przyrównana do białej bułeczki ${ }^{20}$, a Omatsu do czarnej. Pieczywo konotuje tutaj tradycję Zachodu, moga i mobo byli znani z naśladownictwa wzorców zachodnich (fryzura, strój, rozrywki), zatem porównanie inne niż do czegoś zachodniego byłoby nie do przyjęcia, naruszałoby nowoczesny charakter en-

17 Wszystkie tłumaczenia, o ile nie podano inaczej, pochodzą od autorki.

18 E. Seidensticker, The "Pure" and The "in-Between" in Modern Japanese Theories of the Novel, "Harvard Journal of Asiatic Studies" 1966, Vol. 26, s. 174-186.

19 Jedna z dzielnic Tokio.

20 W oryginale jest to 麺麭, złożenie, które furigana odczytuje jako pan, czyli chleb, pieczywo. Wybrałam słowo „bułeczka” ze względu na konotowany przezeń obraz. 
tourage'u Okimi, a Akutagawa zbyt dbał o szczegóły swoich historii, by przeoczyć taki fakt. Nowoczesna dziewczyna po prostu musi być porównana do czegoś nowoczesnego. A jednocześnie jest to zapowiedź częstych dualistycznych zestawień, jakie pojawią się jeszcze w jego twórczości. To „pęknięcie” kulturowe i napięcie istniejące na jego granicach stało się źródłem psychicznego niepokoju samego pisarza.

Nowoczesność Okimi jest poddana humorystycznej krytyce podczas opisu jej niewielkiego pokoju na poddaszu. Na biurku stoją między innymi Hototogisu, Zbiór wierszy Tōsona, Życie Matsui Sumako, Carmen i inne. Akutagawa zauważa jednak z żalem, że „niestety, nie widać tu ani jednego tomiku moich opowiadań”. Większość pozycji na biurku Okimi to powieści sentymentalne, jak Hototogisu, będące zmyśloną historią, zatem - skoro jego samego zaliczano do piszących zmyślenia - również powinien się tam znaleźć. W tym momencie urywa się kontrola autora nad postacią i prowadzoną historią - z łatwością mógłby wprowadzić swoje utwory do środka życia Okimi, ale Akutagawa tego nie robi. On nawet nie opisuje już jej życia jako narrator, ale jako postać rzeczywista, która weszła do wnętrza historii i śledzi świat opisywanej dziewczyny. Dochodzi do połączenia autora z opowiadaną historią, do przedziwnej struktury całego opowiadania, gdzie czasem nie wiadomo, kto w danym momencie ma głos - czy Akutagawa-Autor czy też Narrator, stapiający się czasem z Autorem w jedną postać. Wyraża swoją subiektywną opinię, przestaje być bezosobowym obserwatorem, zwłaszcza że ironia nigdy nie jest obiektywna. Od czasu do czasu wyzwala się i z tej roli, powracając do swojej funkcji jako Autora, zwłaszcza w zakończeniu, będącym dopełnieniem początku, kiedy kpi z krytyków, mówiąc: „Żegnaj, Okimi. Wyrusz na miasto tak jak wyruszyłaś wczoraj - radośnie, odważnie - tylko po to, by być zmiażdżoną przez krytyków!”. Okimi to w tym momencie hipostaza samego pisarza, który jest przekonany, że bez względu na to, co napisze, czy zmyślenie, czy nowelkę shishōsetsu, i tak krytyka pozostanie mu nieprzychylna. We wstępie liczy na przychylność czytelników (choć ten fragment również nie jest pozbawiony sarkazmu), w zakończeniu drwi z krytyków, wplatając dwie wielkie siły stojące za odbiorem dzieła literackiego w jedną historię.

Pokój i życie Okimi doskonale ilustrują Japonię okresu Taishō - kraj zmieszanych tradycji, choć żadna z nich nie jest tak naprawdę dobrze rozpoznana, ale razem tworzą trzecią jakość, nieprzynależącą do pozostałych. Akutagawa doskonale zdawał sobie sprawę z tego rozdwojenia, czego zresztą sam był przykładem - świetnie obeznany zarówno z kulturą rodzimą, klasykami chińskimi, jak i literaturą Zachodu - żonglował nazwiskami i pojęciami, choć zapewne nie wszystkie były dla jego czytelników oczywiste ${ }^{21}$. Elementy kultury Zachodu były artefaktami świadczącymi o „nowoczesności”, o dobrym smaku i obyciu w świecie. Kwestią drugorzędną pozostawała autentyczność i znajomość ich znaczenia. Jedna ze ścian w pokoju Okimi jest udekorowana wycinkami z gazet, które Akutagawa opisuje w taki sposób jak ktoś stojący dokładnie przed ścianą, czyli: „na ścianie nad komodą wiszą na pinezkach jakieś trzy, cztery obrazki wycięte z gazet. W samym środku Piękność Ery Genroku autorstwa Kaburagi Kiyokaty, a poniżej małe coś, co ma wyglądać jak Madonna Rafaela. A z kolei ponad Pięknościa Ery Genroku inna kobieta autorstwa Kitamury Shikaia śle namiętne spojrzenia w stronę sąsiada - Beethovena. Choć to Beethoven tyl-

21 Jak pisał Kikuchi Kan:„Drugiego takiego pisarza tak znającego literaturę japońską, chińską i zachodnią, o takim stopniu wyrafinowania i zakresie zainteresowań, już nie będzie". Por. K. Kikuchi, Akutagawa no kotodomo 芥川の事ども(Rzecz o Akutagawie), tekst w wersji elektronicznej dostępny pod adresem: http://www.aozora. gr.jp/ cards/000083/files/1340_19832.html [dostęp: 23.08.2016]. 
ko dlatego, że Okimi uważa go za Beethovena. Prawdę mówiąc, to amerykański prezydent Woodrow Wilson, co nie za dobrze wróży poczciwemu Kitamurze Shikaiowi”. Akutagawa ukazuje tutaj dobrze znany stereotyp - tak jak dla mieszkańców Zachodu wszyscy Azjaci wyglądają tak samo, tak dla Japończyków wszyscy z Zachodu również są do siebie podobni. Wszystko to jednak ma świadczyć o wrażliwości artystycznej Okimi, będącej nastoletnim egzaltowaniem, a i ona sama odczuwa nieznaczną wyższość nad swoją koleżanką z pracy, która zapewne preferuje tradycyjne, mało nowoczesne formy rozrywki.

Opis Okimi jest prosty podobnie jak prosta jest bohaterka - jednak pozostaje przy tym dowcipny - a jej skromny pokój i ciężkie życie pracującej dziewczyny w wielkim mieście spełniają wymogi stawiane literaturze proletariackiej ${ }^{22}$, choć utwór formalnie do niej nie należy. Akutagawa bawi się gatunkami, łącząc je wszystkie w jednym opowiadaniu i czyni to z precyzyjnie odmierzonym wyrachowaniem. Oprócz dokładnego opisu postaci i pokoju (naturalizm), wprowadza do narracji również sytuację pracowników, którzy przybyli do Tokio w poszukiwaniu lepszego życia. Robi to jednak w sposób pozornie lekki, nasycony ironią, wkładając znaczenia w zwyczajne przedmioty codziennego użytku, które nabierają cech niemal symbolicznych, takich jak sztuczny kwiat czy tytułowe cebulki.

$\mathrm{Na}$ stoliku, przy którym Okimi pisze listy (skierowane do bohaterów literackich, warto nadmienić), stoi w szklanym wazonie sztuczna, uszkodzona lilia, która, jak zauważa autor, „gdyby miała wszystkie płatki, zapewne do tej pory ozdabiałaby stolik w kawiarni”. Zdanie przenika sarkazm, ale najpełniej obrazuje zarówno samą Okimi, jak i całą grupę młodych kobiet pracujących w mieście - to one okazują się tymi sztucznymi (nowoczesność!) kwiatami, które są użyteczne, póki jeszcze ładnie wyglądają i są młode. Z drugiej strony uszkodzona, ale jeszcze przynosząca radość lilia stanowi smutne dopełnienie obrazu życia młodej kelnerki - pragnącej lepszego i zapewne piękniejszego życia, którego jedyną namiastką są zdjęcia z czasopism oraz złamany kwiat. Świat literatury i sztuki stanowi dla Okimi ucieczkę przed rzeczywistością, opłatami i cenami ryżu. Bohaterki literackie nie martwią się czynszem oraz posiłkami i na krótką chwilę, kiedy dziewczyna przeżywa ich historie albo tworzy własne, zapomina o troskach dnia codziennego. Akutagawa opisuje łzawe wzruszenia Okimi, ale przyłapuje się na tym, że sam wpada w pułapkę, mówiąc: ,jeśli nie będę ostrożniejszy, to sam ulegnę sentymentalizmowi. Ja, według krytyków, osoba bez serca i ze zbytnią ilością rozumu!”. Negi są wewnętrznie sprzeczne - każdy nazbyt „sentymentalny” opis jest natychmiast kontrowany ironicznym komentarzem, których liczba i analiza przekracza możliwości jednego artykułu. Nieprzyjemne kwestie są podane w pozornie lekki sposób, tak jakby Akutagawa przez kpinę pokazywał to, co dokładnie sobie zaplanował, ale miało to wyglądać na przypadek, na pisanie „na bieżąco”, stąd komentarze odautorskie.

Tanaka, obiekt westchnień kelnerki, przedstawiciel mobo, jest scharakteryzowany w zupełnie inny sposób, całkowicie pozbawiony jakiejkolwiek sympatii. Choć usiłuje uwieść Okimi i zaprasza ją na spotkanie, to tak naprawdę obiektem największej namiętności Tanaki jest on sam. O ile „nowoczesne dziewczyny” takie jak Okimi budzą współczucie i sympatię czytelnika (oraz autora), to Tanaka okazuje się pretensjonalnym, egoistycznym, pseudoartystycznym pozerem, z czego gdzieś głęboko zdaje sobie sprawę nawet Okimi („wyczuwa,

22 Okres Taishō to czas rozmaitych ruchów, między innymi proletariackich i socjalistycznych. Opisywanie problemów społecznych mogło okazać się jednak fatalne dla pisarzy, stąd też wycofanie ku shishōsetsu, jako bezpiecznej formie ekspresji artystycznej. 
że jej Lancelot skrywa coś niejasnego”), mimo że fantazjując na jego temat, jej serce „tłucze się w piersi niczym fale sztormowego morza lub też silnik przyspieszającego autobusu”. Akutagawa opisuje młodego „powiedzmy, że artystę” poprzez jego rozliczne talenty - grę na skrzypcach, malowanie, komponowanie wierszy, grę na lutni biwa i w utagaruta ${ }^{23}$, choć przyznaje, że nie wie, gdzie kończy się praca, a zaczyna hobby. Nie jest kimś wyjątkowym i Akutagawa pisze: „podczas kiedy ja męczyłem się z jego opisem, Okimi wstała od swojego biurka i przez otwarte okno wygląda w zimną, księżycową noc”. Czyżby więc Okimi wyrwała się autorowi? Kim tak naprawdę ona jest, skoro nawet autor nie ma kontroli nad tym, co robi dziewczyna? Opowiadanie ma swój finał w romantycznym spotkaniu pary, zrujnowanym przez stragan z warzywami, przed którym Okimi dostrzega pęczki cebulek po 4 seny. Natychmiast znikają wizje słowików i róż, a wracają rozmaite rachunki i koszty utrzymania, a sam Tanaka czuje, że perspektywa przytulnego pokoju i wieczoru z Okimi zaczyna przypominać piramidki czterosenowych pęczków cebulek.

\section{Walka kraba z małpą (Saru kani gassen)}

Ten rodzaj humoru jest subwersyjnym sposobem przekazania subiektywnej prawdy o świecie, tym Bachtinowskim „światoodczuciem”, obecnym w niektórych historiach Akutagawy, który w humor, ironię i sarkazm ubierał to, o czym nie mógł napisać wprost, ale co staje się czytelne, jeśli tylko przyjrzymy się opowiadaniom dokładniej. Na drugim krańcu spektrum stoi jednak destrukcyjny rodzaj humoru, o którym wspominał Bełkot i który przenika ostatnie utwory Akutagawy, zwłaszcza Kappy $(1927)^{24}$. Między Negi a Kappami istnieje przepaść - stylistyczna, tematyczna, konstrukcyjna. Historię o cebulkach, choć gorzką, podano w bardzo przemyślnie skonstruowany sposób, historia o kappach jest inna, ironia jest w niej mniej subtelna, a dominujący sarkazm ukazuje całe wykoślawienie i groteskę realnego świata widzianego oczami Akutagawy. Kappy ukazują (czarny) humor i ironię człowieka, który już nie widzi przed sobą żadnej ścieżki. Jednak między Negi a Kappami sytuuje się Saru kani gassen (1923) - ciąg dalszy dobrze znanej bajki pod tym samym tytułem, jadowita satyra na społeczeństwo japońskie. Została tu skrytykowana praca systemu prawnego („Świadkowie mówili, że [adwokat] litościwie ocierał pot z czoła kraba, powtarzając $\mathrm{mu} \gg$ by się poddal«. Nikt nie jest w stanie ustalić, czy owo »poddaj się« dotyczyło akceptacji kary śmierci, czy też astronomicznego rachunku za usługi adwokackie"), filozofia, dawne wartości jak bushidō, środowiska inteligenckie, buddyzm, wpływ wychowania i dziedziczności, działanie prasy, ruchy socjalistyczne, kapitalizm („W nocy, kiedy wykonano na nim wyrok, zarówno sędzia, prokurator, adwokat, dozorca więzienia, kat, a także kapelan, spali snem sprawiedliwego przez 48 godzin. Co więcej, wszyscy później przekazali, że śnili o wrotach do raju. Według nich raj wyglądał jak wielki dom handlowy zbudowany na wzór feudalnego zamku”), a w zakończeniu autor nazywa krabami czytelników, których czeka dokładnie taki sam los. Akutagawa zachował nawet formę bajki, łącznie z finalnym

${ }^{23}$ Gra karciana polegająca na dopasowaniu do siebie fragmentów wierszy znanych poetów.

${ }^{24}$ W Polsce opublikowane jako W krainie wodników, [w:] R. Akutagawa, Życie pewnego szaleńca i inne opowiadania, tłum. M. Melanowicz, Warszawa 1998. 
morałem, a humorystyczny ton pozwolił mu rozprawić się ze społeczeństwem bez narażania się na wrogość cenzury. $Z$ historii kraba, któremu prócz pewnego parlamentarzysty nie współczuła ani jedna osoba, z autorem włącznie, wyłania się nieprzyjemny obraz. Egoizm oraz konformizm - to dwie cechy, które zdają się dominować w zachowaniach dramatis personae. To już nie jest ironiczne, choć niepozbawione wdzięku, odmalowanie społeczeństwa jak w Negi, ale ostra krytyka całego kraju. I tylko humor powstrzymuje ten głęboko negatywny obraz Japonii przed popadnięciem w skrajność defetyzmu, jak w przypadku historii o kappach.

\section{Kappy}

Opowiadanie Kappy posiada podwójnego narratora - innego we wstępie i innego w dalszych 17 rozdziałach ${ }^{25}$. Drugim jest pacjent nr 23 szpitala dla obłąkanych i to on opowiada swoją historię pobytu w kraju kapp pierwszemu. Utwór jest wzorowany na swiftowskich przygodach Guliwera w kraju Liliputów, a same kappy stanowiły jeden z tematów, o których Akutagawa rozmyślał wręcz obsesyjnie ${ }^{26}$. Świat kapp jest nie tylko Bachtinowskim „światem na opak”, jest czymś więcej - samą Japonią, która właśnie w taki sposób jawiła się Akutagawie stojącemu już na rozchwianym moście między szaleństwem a spokojem, zatem niektóre elementy cywilizacyjne są bardzo podobne. W Kappach do głosu doszły wszystkie ciemne elementy społeczeństwa oraz lęki samego autora. Nienarodzone kappiątko jest pytane o zgodę na przyjście na świat, odmawia, jako jeden z powodów podając chorobę umysłową ojca, którą mogłoby odziedziczyć. Aborcja, jaka następuje później, pełni rolę zastępczej śmierci samego Akutagawy. Nie jest to zresztą jedyna śmierć w całej historii - inna to samobójstwo.

Obraz kapp jest obrazem Japonii w odwróconym, pękniętym zwierciadle, jest również niepokojąco profetyczny - historia wojen z wydrami, przerabianie kapp na posiłki dla wojska, różne prowokacje mające wywołać walki na granicy. Społeczeństwo kapp ma swoich poetów (obowiązkowo długowłosych), lekarzy, cynicznych kapitalistów, socjalistów, filozofów, policjantów, wydawców oraz „straszne samiczki” polujące w celach miłosnych na samców. W przeciwieństwie do Japonii ocenzurowana jest jednak muzyka, nie tekst, ponieważ inspektorzy cenzury, jak wszystkie kappy, są pozbawione słuchu muzycznego i uważają, że bezpieczniej ocenzurować każdy utwór, bo może okazać się reakcyjny i wywrotowy. Brutalnej krytyce zostało poddane czytelnictwo - książki są produkowane z wykorzystaniem sproszkowanego mózgu osła będącego nieodzownym składnikiem. Jest to sarkastyczna uwaga wymierzona zarówno w niewybredny gust czytelniczy, jak i wydawnictwa masowo publikujące utwory wątpliwej jakości.

\footnotetext{
25 W ostatnim występują obaj.

26 Por. Y. Sekiguchi, A Study of Akutagawa's "Kappa" (,Kappa" o yomu - Ryūnosuke no seizon e no toikake -

「河童」を読む一龍之介の生存への問いかけ一),“The Tsuru University Review” 2009, No. 70. Sekiguchi wskazuje też na ważny powód inspiracji - chorobę psychiczną Swifta.
} 


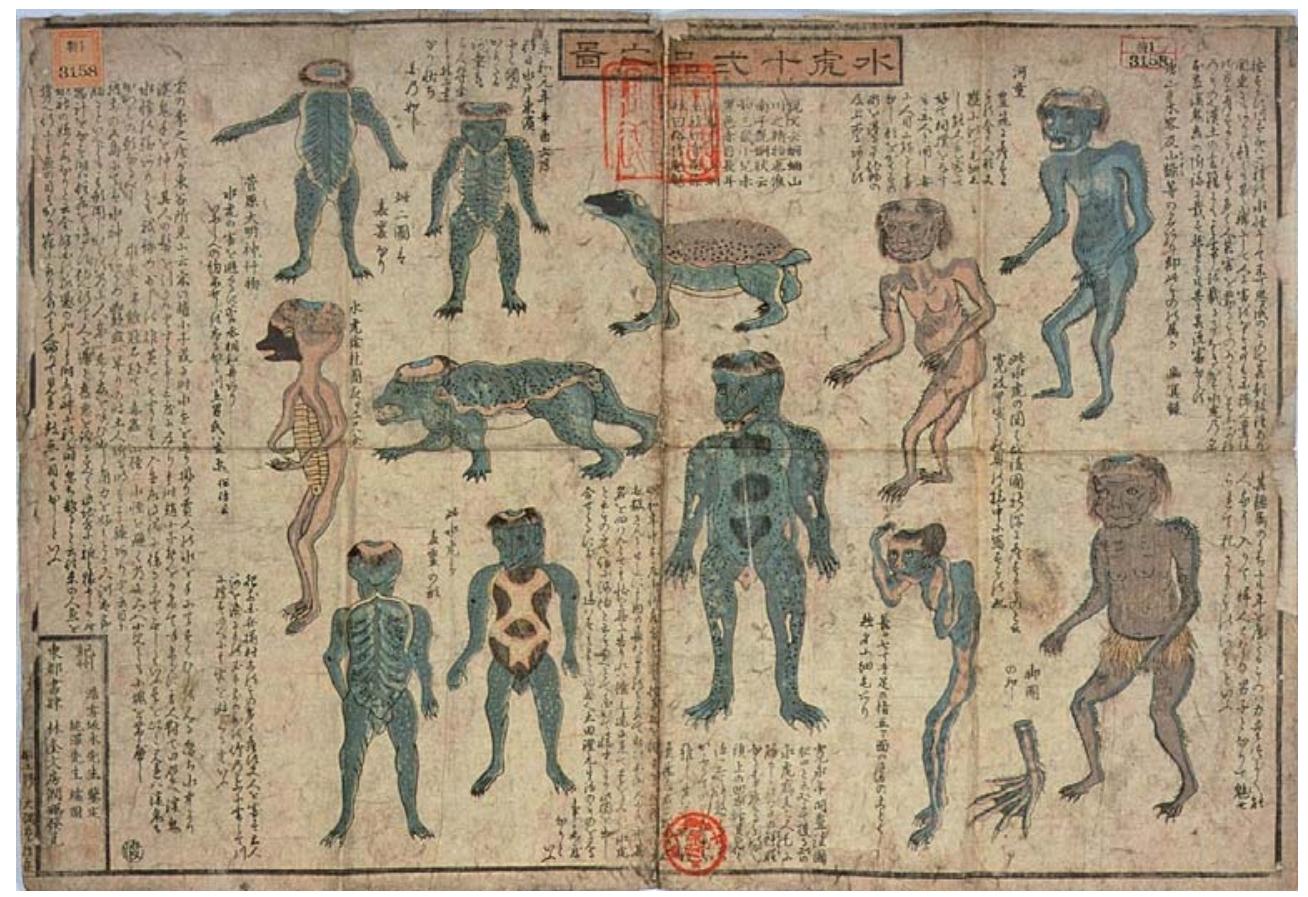

Wizerunek kappy przedstawiony na Ilustracjach 12 typów kapp

(Suiko jūni hin no zu 水虎十二品之図) z połowy XIX wieku; autorstwo: bracia Sakamoto Kōen i Juntaku (na podstawie Wikimedia Commons; dostęp: 25.10.2017).

Narrator, który wpadł do krainy kapp, nauczył się ich języka, poznał obyczaje i zaprzyjaźnił się z kilkoma. Z początku wiele go dziwiło, ale kiedy wrócił do świata ludzi, okazało się, że to właśnie społeczeństwo kapp stało się mu bliższe - tak bliskie, że został odesłany do szpitala dla umysłowo chorych, gdzie, po konfrontacji z ludźmi, zapragnął powrotu do świata tych wodnych istot ${ }^{27}$. W 1927 roku już tylko taka postać mogła być narratorem opowiadania, zatem jej oczami oglądamy świat kapp i jej słowa są jedynym świadectwem wydarzeń. Humor w Kappach łagodzi nieco groteskowość świata przedstawionego, ale nie potrafi już utrzymać go w całości, będąc specyficznym rodzajem destrukcyjnego humoru groteskowego, zakrzepłą w upiornym uśmiechu maską. Ironia i sarkazm, występujące obficie i w bardzo dobrze zaplanowanej formie językowej i kulturowej są niemalże organiczną częścią dystopijnego świata kapp. Już nie wspierają narracji, nie łagodzą opisów trudnych problemów, nie służą nawet nadaniu sensu światu, który sprawia wrażenie nonsensownego - są wyrazem rezygnacji i czarnego humoru człowieka, który w groteskowym świecie kapp widzi więcej sensu i mniej chaosu niż we własnym.

\footnotetext{
27 Narrator używa słowa kaeru i podkreśla, że chodziło mu właśnie o to słowo, a nie iku. Pierwsze oznacza „wrócić” i jest używane tylko w przypadku domu, stron czy też kraju rodzinnego. Iku oznacza „pójść”, „udać się".
} 


\section{Podsumowanie}

Powyższe trzy przykłady ilustrują, w jakiej formie humor oraz ironia zostały włączone do narracji Akutagawy. Utwory wybrano nieprzypadkowo - Negi to wczesny okres twórczości i taka jest też ironia - lekka, precyzyjna, finezyjna, autor bawi się słowami, formami narracji. Ironia jest popisem zręczności językowej, jeszcze nie próbą stworzenia struktury, która odgradza, paradoksalnie normalizuje chaos świata rzeczywistego, czyli Japonii lat dwudziestych. Saru kani gassen to środkowy, kiedy Akutagawa częściowo odarł swój świat ze złudzeń młodości, ironia jest dokładna, ale już zbrutalizowana, a Kappy napisał niedługo przed swoją śmiercią, kiedy nawet warsztat pisarski poddał się ogólnej destrukcji światopoglądu i życia autora. Humor i ironia były sposobem opisu otaczającego go świata, Akutagawa bronił się przed zaakceptowaniem rzeczywistości, która rozpadała się w jego umyśle w coraz większy chaos, i kwestionowal jej logikę oraz sposób funkcjonowania, przez soczewkę ironii pokazując, jak naprawdę funkcjonuje społeczeństwo, czy też raczej - jak on je widział. Nie była to optymistyczna wizja, ponieważ optymizm był towarem deficytowym w świecie Akutagawy. Autor bronił się przed popadnięciem w całkowity nihilizm i humor pełnił rolę kontaktu z rzeczywistością. Kappy to jego ostatnie opowiadanie z elementami ironii i humoru, choć tym razem bardzo już gorzkiego. Chaos nie jest w opowiadaniach Akutagawy owych ironii i humoru przeciwieństwem, są one raczej jego swoistym dopełnieniem. Chaotyczny był świat zewnętrzny - Japonia modernizująca się w błyskawicznym tempie, przyswajająca sobie artefakty kultury zachodniej, a jednocześnie zaostrzająca cenzurę i ucisk polityczny. Był to kraj nacjonalistycznych haseł i poczucia niższości względem mocarstw zachodnich, kraj sporów literackich na łamach czasopism oraz brutalnego wynarodowiania mieszkańców Półwyspu Koreańskiego - słowem, był to okres chaosu, a jedynym sposobem, by mu nie ulec, był humor. Kiedy i on zawodził - pojawiało się przeczucie absurdu, o którym Albert Camus pisal, że jest kondycją człowieka, który żyje w świecie bez Boga, wartości i fundamentalnych prawd, a poszukiwanie jakichkolwiek wartości jest daremne ${ }^{28}$. Chaotyczny był również świat wewnętrzny Akutagawy - obsesja zbliżającej się, odziedziczonej choroby umysłowej, zmagania z materią twórczą, niechęć krytyków, podupadające zdrowie. Według Roberta Previne’a, psychologa, śmiejemy się również wtedy „kiedy jesteśmy wystraszeni, zaskoczeni lub przerażeni” ${ }^{29}$, a Ted Cohen wprost twierdzi, że humor jest próbą „wyrwania kłów, udomowienia czegoś, czego generalnie nie da się ułagodzić. [...] Jest to sposób na przejęcie kontroli nad czymś, czego nie jesteśmy w stanie kontrolować”30. Tworząc opowiadania o rygorystycznej strukturze, nasycone subtelnym (bądź nie) humorem, Akutagawa próbował zapanować nad chaosem obu światów, w którym przyszło mu żyć - wewnętrznym i zewnętrznym. Jego ostatnie dzieła wyraźnie jednak wskazują, że była to metoda niewystarczająca - tak długo spoglądał w nietzscheańską otchłań, że ta go w końcu pochłonęła.

28 A. Camus, Mit Syzyfa i inne eseje, tłum. J. Guze, Warszawa 2004.

29 Za: A. Gini, Seeking the Truth of Things. Confessions of a (Catholic) Philosopher, Chicago 2011, s. 77.

30 Ibidem. 


\section{Bibliografia}

Antropologia twórczości słownej. Zagadnienia i wybór tekstów, red. Agnieszka Karpowicz, Katarzyna Hagmajer-Kwiatek, Justyna Kowalska-Leder, Warszawa: Wydawnictwa Uniwersytetu Warszawskiego, 2012.

Bachtin Michaił, Twórczość Franciszka Rabelais'go a kultura ludowa Średniowiecza i Renesansu, tłum. Anna i Andrzej Goreń, Kraków: Wydawnictwo Literackie, 1975.

Barthes Roland, Śmierć autora, tłum. Michał P. Markowski, „Teksty Drugie” 1999, nr 1/2 (54/55).

Bełkot Andrzej, Karnawalizacja jako pojęcie ludyczne, „Homo Communicativus” 2010, nr 4.

Camus Albert, Mit Syzyfa i inne eseje, tłum. Joanna Guze, Warszawa: Wydawnictwo Muza, 2004.

Culler Jonathan, Teoria literatury, tłum. Maria Bassaj, Warszawa: Prószyński i S-ka, 1998.

DiNitto Rachel, Return of the "Zuihitsu": Print Culture, Modern Life, and Heterogeneous Narrative in Prewar Japan, "Harvard Journal of Asiatic Studies" 2004, Vol. 64, No. 2.

Foucault Michel, Kim jest autor?, tłum. Michał P. Markowski, [w:] idem, Powiedziane, napisane. Szaleństwo i literatura, red. Tadeusz Komendant, Warszawa: Fundacja Aletheia, 1999.

Gadamer Hans-Georg, Prawda i metoda: zarys hermeneutyki filozoficznej, tlum. Bogdan Baran, Warszawa: Państwowe Wydawnictwo Naukowe, 2015.

Gini Al, Seeking the Truth of Things. Confessions of a (Catholic) Philosopher, Chicago: ACTA Publications, 2011.

Głowiński Michał, Ironia jako akt komunikacyjny, [w: ] Ironia, red. Michał Głowiński, Gdańsk: słowo/obraz terytoria, 2005.

Iles Timothy J.F., "Akutagawa Ryunosuke: Three Themes”, praca magisterska napisana na Uniwersytecie Columbia, New York 1992.

Kikuchi Kan, Akutagawa no kotodomo芥川の事ども(Rzecz o Akutagawie), http://www.aozora. gr.jp/cards/000083/files/1340_19832.html [dostęp: 23.08.2016].

Maj Krzysztof M., Eutopie i dystopie. Typologia narracji utopijnych z perspektywy filozoficzno-literackiej, „Ruch Literacki” 2014, R. LV, z. 2 (323).

Seidensticker Edward, The "Pure" and The "in-Between" in Modern Japanese Theories of the Novel, "Harvard Journal of Asiatic Studies" 1966, Vol. 26.

Sekiguchi Yasuyoshi, A Study of Akutagawa's “Kappa” („Kappa” o yomu - Ryūnosuke no seizon e no toikake -「河童」を読む一一龍之介の生存への問いかけ一), “The Tsuru University Review”2009, No. 70.

Silverberg Miriam Rom, Erotic Grotesque Nonsense: The Mass Culture of Japanese Modern Times, Berkeley: University of California Press, 2006.

Stownik języka polskiego, red. Witold Doroszewski, Warszawa: PWN, http://www.sjp.pwn.pl/doroszewski/ [dostęp: 20.08.2016]. 